Crohn's disease (not specifically illustrated 126). It is noted in the diagnostic notes at the rear of the book, but readers do not look there spontaneously as they read through the sections.

In the caption to Figure 105, there would appear to be a confusion between Tzank cells and the Tzank test, in the latter, the intercellular bridges are lost in the prickle cell layer and the cells are rounded - this is the diagnosis for Pemphigus Bullae, but Tzank cells are the cells containing virus inclusion bodies found in association with the herpes and chicken pox viruses. The same comment can be made regarding caption 109.

It is surprising that the comment on Epanutin Hyperplasia was made regarding oral hygiene in a somewhat derogatory manner - it does not occur in excellent oral hygiene cases and also there is no mention of an apparently similar condition found in patients on Sodium Valporate (Epilim), furthermore, the vascular lesions shown are not usually neoplasms and should be put in a separate category; mention could have been made of 2 other inherited conditions, gingival fibromatosis with hypertrichosis and Hunter-Hurler syndrome with its mixed bone/mucosa changes. The state of a Mongol's tongue and mouth would be better shown that cancrum oris.

However, although one may be critical of certain aspects of the book, as a whole it makes a useful reference for the undergraduate and early postgraduate; also for general practitioners. The format would be better if the more common conditions, particularly on ulcers, came first and the notes came at the end of each section instead of the end of the book where they tend to be overlooked and to break the continuity.

\section{Essentials of Radiology}

By P. M. Bretland. Pp. 178, soft cover, illustrated. Butterworths: London, 1978. $£ 8.95$.

This is a soft covered book consisting of 178 pages. It has numerous line drawings for instruction and 230 problem radiographs for the reader to interpret. The radiological subjects covered are the chest, abdomen, bones and skull. No mention is made of contrast studies, and the author concentrates on plain film interpretation. There is a list of suggested books for further reading included.

In the preface Dr Bretland says that the book is intended for the student in his first clinical year. The reviewer was quite pleased when he read this, as he has felt for a long time that there is a great need for such a book in diagnostic radiology. However, he thinks that the first year clinical student might find some of the pathological disorders beyond his grasp. It is possible, of course, that he may be stimulated to refer to other medical text books for elucidation. The content would be of greater value to the young postgraduate and indeed helpful to those intending to pursue a career in diagnostic radiology. The emphasis is on a basic scheme of approach and in this the author has succeeded. The steps to be taken in "reading" the plain X-rays of the areas covered are very clearly stated.

This reviewer can find no fault with the text, which is well written and easy to read. However, he found many of the photographic prints difficult to interpret, because the lesions were not clearly seen. This is a fault of the reproduction, and the reviewer is worried lest many non-radiological readers might be discouraged by a failure to achieve a worth-while diagnostic score. Even on reading the well written descriptive answers, the lesions in many were still not visible. This is unfortunate because the radiographs are well chosen and cover a wide area of different pathologies. It is hoped that in future editions this fault will be corrected.

Allowing for this, the reviewer would recommend this book to all those students and young postgraduates who are looking for a clear account of how to interpret the plain radiographs they will see in daily practice. This has been a relatively neglected area in most radiological text books and Dr Bretland has gone some way to correcting it.

\section{Gastroenterology. An Integrated Course}

(2nd Edition). By Iain E. Gillespie and T. J. Thomson. Pp. 294, illustrated, soft cover. Churchill Livingstone: Edinburgh, 1977. £3.95.

This book, which is based on a course given to 4th-year students at Glasgow Medical School, is primarily intended for an undergraduate audience. An integrated approach has been adopted and the whole of medical and surgical gastroenterology, including a chapter on the mouth, and a chapter on gastrointestinal disease in general practice are dealt with in 284 pages. Consequently only basic facts are presented and controversial issues are strictly eschewed. Something of a surgical bias is also detectable, with only 34 pages dealing with liver disease, whereas 22 pages are devoted to the proctodaeum.

Despite its multiple authorship the book is ably and uniformly written and it is well illustrated throughout. Simple line drawings are employed to clarify the text and there are good quality reproductions of X-ray and histological material. The book should appeal particularly to those medical students desirous of a didactic approach. It is of doubtful value, however, for the postgraduate.

\section{Gynaecological Laparoscopy \\ The Report of the Working Party of the Confidential Enquiry into Gynaecological Laparoscopy}

Edited by G. Chamberlain and J. Carron Brown. Pp. 165, illustrated. Royal College of Obstetricians and Gynaecologists: London, 1978. £2.50.

A survey of patients undergoing gynaecological laparoscopy in the United Kingdom was carried out between April 1st 1976 and March 31 st 1977 and the information contained in over 50000 completed questionnaires has been duly analysed and presented in book form. A facsimile of the questionnaire form is included at the end of the report.

It is difficult to see who will benefit from reading this report, nor is it possible to assess whether the results justify the enormous expenditure of effort and time on the part of so many practising doctors. Those who have been using the technique for a number of years are not going to learn anything that they were not aware of already and those in training, both gynaecologists and anaesthetists, will learn more quickly and in greater depth if they work for seniors already versed in the procedure. It is to be hoped that this report does not open up a floodgate for similar ones dealing with other forms of endoscopy. All investigational techniques carry some hazard and it behoves clinicians to weigh up advantages of any technique before employing it. Once adopted, then the risk factors will be taken into account each time it is used and a report such as this is not going to influence the decision.

Man at High Altitude. The Pathophysiology of Acclimatization and Adaptation

By Donald Heath and David Reid Williams. Foreword by Sir Cyril Astley Clarke. Pp. 292, illustrated. Churchill Livingstone: Edinburgh, London, New York. £12.50.

This book incorporates the wide personal experience over the past decade of the authors in the study of Man at High Altitude in the Andes and subsequently extrapolated to the laboratories of the Department of Pathology at the University of Liverpool. The pathophysiology of acclimatization and adaptation to high altitudes is described dealing both with the clinical and pathophysiological aspects of all organ systems which may be effected. This book has particular 